Shoesmiti, J. G. (1960). J. gen. Microbiol. 22, 528-535

\title{
The Measurement of Bacterial Motility
}

\author{
BY J. G. SHOESMITH* \\ Department of Bacteriology, University of Manchester
}

\begin{abstract}
SUMMARY : Bacterial motility was measured by a simple method which consists of counting the number of organisms which pass across a small aperture in a given time. The count is proportional to the bacterial concentration in the suspension and also to the average speed of the bacteria. A slight increase in the viscosity of the suspending medium above that of a buffer solution has the effect of increasing motility; further increase in viscosity decreases it.
\end{abstract}

The quantitative assessment of bacterial motility has usually been made by methods which are either tedious or do not give a direct indication of the speed of movement. Ôgiuti (1936) measured the time taken for an organism to move over a known distance; by applying the measurement to several organisms the average speed could be determined. Other methods involve the observation of the spread of bacteria through agar or filter paper, but the results take several hours to obtain and may be influenced by the rate of growth of the organism and by chemotactic effects (Ljachowetzky, 1911; Clowes, Furness \& Rowley, 1955). The method to be described has been adapted from a technique which has been used in the investigation of Brownian movement (Glasstone, 1948). In this method the field visible under the microscope is greatly diminished so that particles in this field can be counted at a glance. By counting the number of bacteria passing across such a field in a given time it was hoped to assess the motility in a simple, rapid and quantitative manner.

\section{METHODS}

Organisms. The bacteria used were: a strain of Pseudomonas viscosa (Sherris, Preston \& Shoesmith, 1957); a strain of Bacillus brevis (NCTC 7577); a strain of Escherichia coli (Department of Bacteriology, Manchester).

Preparation of motile suspensions. Pseudomonas viscosa was grown on nutrient agar at $23^{\circ}$ for $18-20 \mathrm{hr}$. and the growth suspended in $0.04 \mathrm{M}$ phosphate buffer (Sörensen, pH 7·2). Bacillus brevis and Escherichia coli were grown in a shallow layer of peptone medium ( $1 \%$ Oxoid peptone; $0.5 \% \mathrm{NaCl}$; $\mathrm{pH} \mathrm{7.4)}$ at $30^{\circ}$ for 18-20 hr. The cultures were centrifuged and the respective deposits resuspended in buffer containing $0.1 \mathrm{M}-\mathrm{NaCl}$ and $0.02 \mathrm{M}$-phosphate (pH 7.2). The bacterial suspensions were continuously aerated by gentle mechanical shaking in Erlenmeyer flasks. Bacteria in samples removed from these suspensions maintained a constant motility, according to 'motility counts' for at least $15 \mathrm{~min}$.

Microscopical observation. Samples of suspension were drawn into flat

* Present address: Department of Bacteriology, Guy's Hospital Medical School, I.ondon, S.E. 1 . 
capillaries (Sherris et al. 1957) and observed with a $2 \mathrm{~mm}$. oil-immersion objective by phase contrast.

Measurement of motility. A $\times 10$ eyepiece was fitted in its focal plane with an opaque disk which had a hole $0.8 \mathrm{~mm}$. in diameter in the centre. This permitted the observation of a field $10 \mu$ in diameter. The motility was assessed by counting the number of bacteria which traversed this field in a given time. This 'motility count' was routinely made over 1 min., repeating this in two other parts of the capillary, and taking the mean.

Increase in viscosity of suspending fluids. The materials used to increase the viscosity of the suspending medium were dissolved in water at the indicated concentrations and comprised the following: aqueous solutions of gelatin, $5 \%(w / v)$, adjusted to $\mathrm{pH} 7 \cdot 2$ with $\mathrm{NaOH}$; methylcellulose (British Drug Houses Ltd.), $2.5 \%$ (w/v); carragheenin, $1 \%(w / v)$; dextran (Benger's Ltd., Holmes Chapel) of intrinsic viscosity $0 \cdot 4,10 \%(w / v)$. Methylcellulose and carragheenin were dissolved as far as possible at room temperature and insoluble material removed by centrifugation; the dextran was brought into solution by heating at $100^{\circ}$.

Bacterial concentration. Total bacterial counts were made on a Thoma counting slide, a suitable dilution being made in $0.25 \%(w / v)$ formaldehyde. Phase-contrast illumination was used and groups of bacteria joined together were counted as single organisms.

Possible sources of error. Experience showed that attention needed to be paid to the following points. The microscope must be adjusted to give maximum contrast and definition. Capillaries with flat parallel sides which cause the minimum amount of distortion should be used. Counts should be made in fields at least $0.04 \mathrm{~mm}$. below the glass-liquid interface. Counts made near the wall of the capillary were apt to be less reproducible and subject to large variations which were due perhaps to bacteria tending to accumulate near the glass. Observations should be made at least $0.5 \mathrm{~cm}$. away from the air interface. When this was done motility remained constant until movement ceased abruptly when dissolved oxygen was consumed. Near the air interface movement continued indefinitely but varied greatly as chemotactic bands began to form (Sherris et al. 1957; Baracchini \& Sherris, 1959). Motility counts greater than $100 / \mathrm{min}$. are too great for accurate observation, and in practice suspensions giving such counts should be diluted.

\section{RESULTS}

Some representative results are as follows. A suspension of Pseudomonas viscosa having an optical density corresponding to Brown's tube no. 5 (Burroughs Wellcome) and containing $2 \times 10^{\circ}$ organisms $/ \mathrm{ml}$. gave a count of 70 organisms crossing the small field per min. This was a suspension in which virtually all the organisms appeared to be motile and the quality of the motility would be assessed as vigorous. After motility had ceased the Brownian movement (judged by the character of the movement, which appeared not to be residual motility) in this suspension gave rise to a count of $4 / \mathrm{min}$. 
A suspension of Bacillus brevis qualitatively showing good motility and containing $0.8 \times 10^{9}$ organisms $/ \mathrm{ml}$. gave a count of $32 / \mathrm{min}$. A suspension of Escherichia coli having moderate motility and containing $0.9 \times 10^{9}$ organisms/ ml. gave a count of $12 / \mathrm{min}$. Since, as is shown below, the 'motility count' is proportional to the bacterial concentration, these results may be expressed in terms of a bacterial concentration of $10^{\circ}$ organisms $/ \mathrm{ml}$.: Pseudomonas viscosa, 35/min.; B. brevis, 40/min.; E. coli, 13/min. Strains of Proteus and Chromobacter which were tested did not show a constant and vigorous motility in the buffer used and were not suitable for the experiments described below.

In the case of Pseudomonas viscosa motility was found to vary from one culture to another and counts from $30 / \mathrm{min}$. to $100 / \mathrm{min}$. have been obtained. The counts obtained using the organisms from any given suspension were, however, reproducible for 2-3 hr. The differences found were therefore due to variations in the conditions of growth and preparation of the suspensions rather than changes in the motility of the suspensions after their preparation. Since the techniques of cultivation, preparation and aeration of the suspensions were similar it is apparent that there are unknown factors which greatly affect the motility of organisms derived from different cultures. Because of this it is difficult to compare quantitatively the motilities of different strains, and the values quoted are merely typical of those obtained.

Reproducibility. A suspension of Pseudomonas viscosa was examined in five capillaries and a total of thirty counts made. The mean value was $63 / \mathrm{min}$. with a standard deviation of $6 / \mathrm{min}$. When the counts were taken in groups of three, as would be done in routine counting, the standard error was $3 / \mathrm{min}$.

\section{The relation between the average speed of motility and the ' motility count'}

The 'motility count' is an expression of the overall motility of a bacterial suspension and depends on three factors: the size of the field observed, which may be made constant; the concentration of bacteria; the average speed of all the bacteria in the suspension. Non-motile bacteria in a suspension decrease the motility count. To determine the relation between the average speed of movement and the motility count it was necessary to measure the average speed directly. Pseudomonas viscosa and several other species including strains of Proteus, Escherichia, Chromobacterium and Bacillus were unsuitable for such measurements as their paths of movement were too irregular. It was found eventually that a strain of Bacillus brevis NCTC 7577 moved in a straight path and could easily be made to maintain good motility. The suspension was diluted to contain $1.6 \times 10^{8} \mathrm{bacilli} / \mathrm{ml}$. The speeds of 20 organisms were measured individually by using an eye-piece scale which extended over almost the whole field of the oil-immersion lens and corresponded to a distance of $100 \mu$. The distances over which the organisms were timed were from 20 to $100 \mu$, and the duration of observations from 2 to 7 sec. Actual speeds ranged from 6 to $32 \mu / \mathrm{sec}$. but the majority of these $B$. brevis organisms had speeds between 10 and $25 \mu / \mathrm{sec}$. The motility count was made with a suspension containing $8 \times 10^{8} \mathrm{bacilli} / \mathrm{ml}$. and was corrected by subtracting from it the 
motility count (average value $3 / \mathrm{min}$.) obtained with a suspension in which movement had ceased through lack of oxygen. The results are shown in Table 1. Preparations 1, 2 and 3 were prepared by similar techniques and indicate the differences that may be found between cultures prepared apparently in the same way. Preparations 4 and 5 had lower motility counts because they were deliberately suspended in buffers with lower $\mathrm{pH}$ values. Such low counts were due to small proportions of motile bacteria rather than to corresponding decreases in their speeds. Nevertheless, the average speed of

Table 1. The relation between average speed of movement of Bacillus brevis and the motility count

\begin{tabular}{|c|c|c|c|c|}
\hline Preparation & $\begin{array}{c}\text { Average speed } \\
\text { of motile } \\
\text { organisms } \\
(\mu / \text { sec. })\end{array}$ & $\begin{array}{c}\text { Proportion } \\
\text { of motile } \\
\text { organisms } \\
(\%)\end{array}$ & $\begin{array}{c}\text { Average speed } \\
\text { of all } \\
\text { organisms } \\
(\mu / \mathrm{sec} .)\end{array}$ & $\begin{array}{l}\text { Motility } \\
\text { count* }\end{array}$ \\
\hline $1, \mathrm{pH} 7 \cdot 2$ & 21 & 100 & 21 & 34 \\
\hline $2, \mathrm{pH} 7 \cdot 2$ & 18 & 100 & 18 & 29 \\
\hline $3, \mathrm{pH} 7 \cdot 2$ & 17 & 80 & 14 & 21 \\
\hline 4, pH $6 \cdot 0$ & 15 & 50 & 7 & 10 \\
\hline 5, pH $5 \cdot 0$ & 10 & 20 & 2 & 4 \\
\hline
\end{tabular}

* The motility counts were obtained with a suspension containing $8 \times 10^{8} \mathrm{bacilli} / \mathrm{ml}$. and the figures in the table have been corrected by subtracting a count of 3 due to Brownian movement.

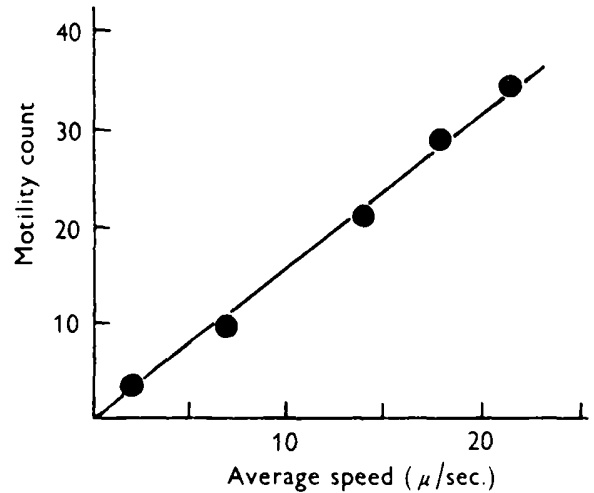

Fig. 1

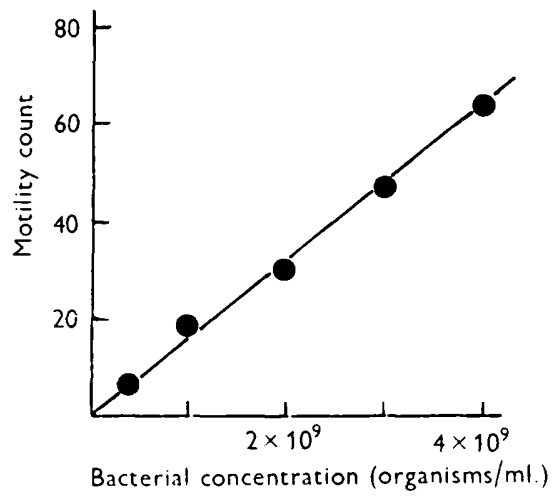

Fig. 2

Fig. 1. The relation between the motility count and the average speed of bacilli in suspensions of Bacillus brevis.

Fig. 2. The relation between the motility count obtained with Pseudomonas viscosa and the bacterial concentration.

the motile organisms in these suspensions was lower than it was in suspensions with a high motility count. The proportion of motile to non-motile organisms was determined by the direct counting of several fields and from this figure the average speed of all the bacteria in the suspension could be calculated. The results (Fig. 1) showed that the motility count was proportional to the average speed of all the bacteria in the suspension when the concentration of organisms was constant. 


\section{The relation between bacterial concentration and the motility count}

The motility count will clearly be affected by the number of motile bacteria in the suspension under examination. As the suspensions used in these experiments were from young cultures which contained a high proportion of motile organisms, the observations could be related to total counts. Direct observations of the relation between bacterial concentration and motility count were made with a suspension of Pseudomonas viscosa containing $4 \times 10^{9}$ bacteria $/ \mathrm{ml}$. and aerated by shaking. No change in the optical density of the suspension occurred during the $2 \mathrm{hr}$. period of the experiment and samples withdrawn at different times during this period gave similar motility counts. Other samples were removed, diluted in buffer and motility counts made. The results (Fig. 2) showed that the motility count was proportional to the bacterial concentration.

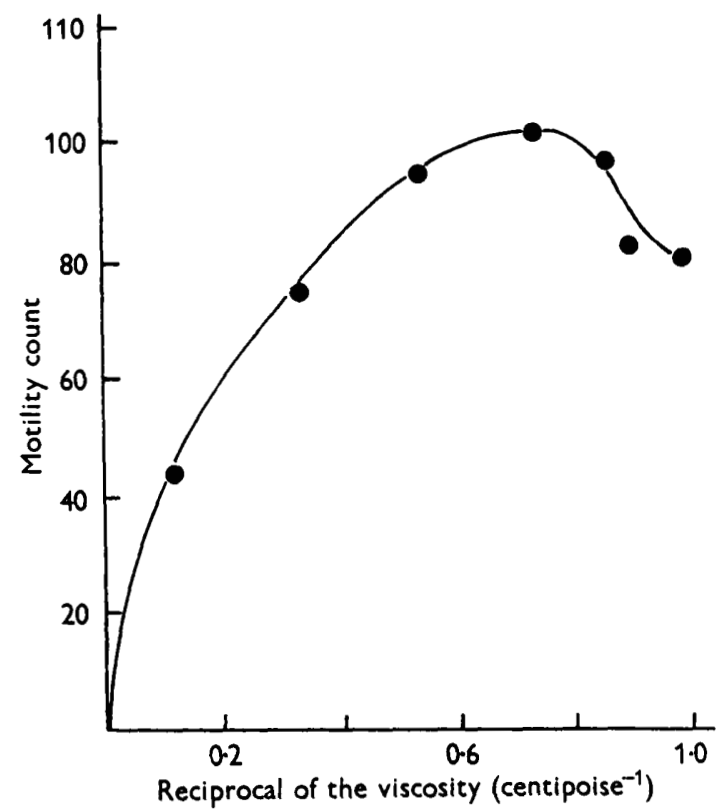

Fig. 3. The effect of methylcellulose on the motility of Pseudomonas viscosa.

The effect of changes of viscosity on motility

Some preliminary investigations were made to determine the effect of increasing the viscosity of the suspending medium on the motility count. Viscosity was measured with an Ostwaldt viscometer at the temperature of the microscope stage $\left(23^{\circ}\right)$. The results of one experiment with Pseudomonas viscosa and methylcellulose are shown in Fig. 3. A suspension of the organism

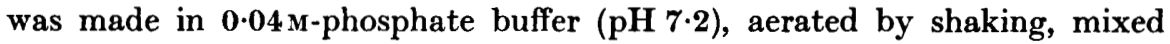


with an equal volume of an aqueous solution of the substance under test and motility counts made. It can be seen (Fig. 3) that a slight increase in viscosity resulted in an increase in the speed of motility. The maximum motility count was about $20 \%$ greater than in buffer alone and was found in solutions having a viscosity of 1.33 centipoise (cps.). From this point increases in viscosity resulted in diminution of motility but the motility did not fall below that in buffer until the viscosity had reached a value of at least 2.5 cps. It is evident ('Table 2) that the motility of Bacillus brevis and Escherichia coli was similarly increased when the viscosity was raised to $1.33 \mathrm{cps}$. by the addition of methylcellulose. Table 2 shows also that the motility of $\boldsymbol{P}$. viscosa was increased by certain concentrations of gelatin and carragheenin, but not by dextran.

Table 2. The effect of changes in viscosity on bacterial motility

\begin{tabular}{|c|c|c|c|c|c|}
\hline Organism & $\begin{array}{l}\text { Viscous } \\
\text { substance }\end{array}$ & $\begin{array}{c}\text { Concentration } \\
(\%, w / v)\end{array}$ & $\begin{array}{l}\text { Viscosity, } \eta \\
\text { (centipoise) }\end{array}$ & $\frac{1}{\eta}$ & $\begin{array}{c}\text { Motility } \\
\text { ( } \% \text { of count } \\
\text { in control)* }\end{array}$ \\
\hline $\begin{array}{l}\text { Pseudomonas } \\
\text { viscosa }\end{array}$ & $\begin{array}{l}\text { Methylcellulose } \\
\text { Methylcellulose } \\
\text { Gelatin } \\
\text { Carragheenin } \\
\text { Carragheenin } \\
\text { Dextran } \\
\text { Dextran }\end{array}$ & $\begin{array}{l}0 \cdot 125 \\
1 \cdot 00 \\
1 \cdot 25 \\
0 \cdot 125 \\
0 \cdot 250 \\
1 \cdot 0 \\
5 \cdot 0\end{array}$ & $\begin{array}{c}1 \cdot 33 \\
7 \cdot 78 \\
- \\
3 \cdot 10 \\
6 \cdot 21 \\
1 \cdot 20 \\
2 \cdot 52\end{array}$ & $\begin{array}{c}0 \cdot 75 \\
0 \cdot 13 \\
- \\
0 \cdot 32 \\
0 \cdot 16 \\
0 \cdot 83 \\
0 \cdot 40\end{array}$ & $\begin{array}{r}123 \\
43 \\
130 \\
112 \\
73 \\
95 \\
55\end{array}$ \\
\hline Bacillus brevis & Methylcellulose & $0 \cdot 125$ & $1 \cdot 33$ & $0 \cdot 75$ & 115 \\
\hline Escherichia coli & Methylcellulose & $0 \cdot 125$ & 1.33 & $0 \cdot 75$ & 140 \\
\hline
\end{tabular}

* In the control, a motility count was made with a suspension of the given organism in 0.02 $\mathrm{M}$-phosphate buffer (pH 7.2) alone.

Investigations on these substances were, however, limited by their properties. The gelling properties of gelatin made it impossible to measure its viscosity, carragheenin often caused agglutination of the bacteria, particularly in high concentrations, and the concentration of dextran needed to increase the viscosity by the required amount was rather high. It is apparent from these results that motility is undoubtedly affected by changes in viscosity; the degree and direction of the change in motility depend, however, on the general properties of the viscous substance as well as on the numerical value of the viscosity.

\section{DISCUSSION}

It has been shown that a simple counting method will give a quantitative overall assessment of the motility of bacteria in a suspension. The numerical value of the motility count obtained is proportional to the average speed of the bacteria and also to the bacterial concentration. When the motility of different suspensions is to be compared quantitatively it is therefore necessary for the bacterial concentration to be constant. Under these conditions, and if motility continues under the required conditions long enough for a count to be made, it should be possible to use the method to investigate the effect of various factors on motility in a quantitative fashion. It would, 
however, be difficult to compare the motilities of bacteria from different cultures. The motility counts obtained with Pseudomonas viscosa and Bacillus brevis varied from culture to culture and so it would be necessary to determine and control the conditions of growth and preparation of suspensions which affect motility before it would be possible to use any method of measuring motility in suspensions to compare the motilities of different strains.

Some experiments to determine the effect of varying the conditions in the suspensions have been carried out in this investigation. An effect of $\mathrm{pH}$ is shown in Table 1. Changes in viscosity did not affect the motility in a simple fashion. The simplest relation between viscosity and the speed of movement would have occurred if the moving bacteria obeyed a law analogous to Stokes's Law, i.e. $F=K \eta v$, where $F$ is the propulsive force, $K$ a constant incorporating the dimensions of the organism, $\eta$ the viscosity of the medium and $v$ the steady speed. In this case if the propulsive force remained constant, the speed would be inversely proportional to the viscosity, and if these considerations also applied to the motility of the whole suspension, the motility count would be directly proportional to the reciprocal of the viscosity. Figure 3 and Table 2 show that with the reagents and bacterial species tested this did not occur; the motility was always greater than predicted by this simple relationship.

This phenomenon has also been touched upon by earlier workers. Ôgiuti (1936) stated that increases in viscosity had little effect on the motion of bacteria, and Pjiper (1947) described the motility of bacteria as being good even when suspended in solutions of methylcellulose having viscosities of up to $50 \mathrm{cps}$. These qualitative observations did not, however, suggest anything more than a deviation from the straight-line relationship. Such deviations might be expected since bacteria are not inert particles but living organisms propelled by flagella and also because the viscous medium does not necessarily possess the same viscous properties when reacting to the movement of bacteria as it does in an Ostwaldt viscometer. Effects of this sort would not, however, decrease the viscosity below that of buffer, and the speed of motility would be expected to fall when viscous substances were present. In practice, the presence of methylcellulose and carragheenin can cause an increase in motility; assuming that the simple theory is correct, this can only be explained by an increase in the propulsive force. It is not clear how this might be achieved, but it is possible that over certain viscosity ranges an increase in viscosity causes an increase in the force exerted by the flagella which outweighs the increase in resistance to movement and results in greater speed.

The author is indebted to the Agricultural Research Council for a Junior Fellowship, and to Dr F. A. Rose (Department of Rheumatism Research, University of Manchester) for a sample of carragheenin. 


\section{REFERENCES}

Baracchini, O.\& Sherris, J. C. (1959). The chemotactic effect of oxygen on bacteria. J. Path. Bact. 77, 565.

Clowes, R. C., Furness, G. \& Rowley, D. (1955). The measurement of speeds of motility in Escherichia coli. J. gen. Microbiol. 13, i.

Glasstone, S. (1948). Textbook of Physical Chemistry, 2nd ed. p. 258. London: Macmillan and Co.

LJAChоwетzкy, M. (1911). Eine neue Methode zum Studium der lokomotorischen Funktion der Bakterien. Zbl. Bakt. (1. Abt.), 57, 180.

ÔGIUTI, K. (1936). Untersuchungen über die Geschwindigkeit der Eigenbewegung von Bakterien. Jap. J. exp. Med. 14, 19.

Pisper, A. (1947). Methyl cellulose and bacterial motility. J. Bact. 53, 257.

Sherris, J. C., Preston, N. W. \& Shoesmith, J. G. (1957). The influence of oxygen and arginine on the motility of a strain of Pseudomonas sp. J. gen. Microbiol. 16, 86 .

(Received 28 September 1959) 